\title{
114. APRENDER E PARTILHAR: A DIDÁTICA SOLIDÁRIA E SOCIALMENTE RESPONSÁVEL DA UNIVERSIDADE POPULAR TÚLIO ESPANCA DA UNIVERSIDADE DE ÉVORA ${ }^{1}$
}

\author{
Bravo Nico', Lurdes Pratas Nico², Vanessa Sampaio 3 , Daniela Lopes ${ }^{4}$, \\ Patrícia Ramalho ${ }^{5}$ \\ ${ }^{1}$ Universidade Popular Túlio Espanca da Universidade de Évora (PORTUGAL), \\ ibn@uevora.pt \\ ${ }^{2}$ Universidade Popular Túlio Espanca da Universidade de Évora e Direção Geral de \\ Estabelecimentos Escolares / Delegação Regional do Alentejo (PORTUGAL), \\ Ipnico@uevora.pt \\ ${ }^{3}$ Universidade Popular Túlio Espanca da Universidade de Évora (PORTUGAL), \\ vaas@uevora.pt \\ ${ }^{4}$ Universidade Popular Túlio Espanca da Universidade de Évora e SUÃO-Escola \\ Comunitária de São Miguel de Machede (PORTUGAL), suao.fazerbem@gmail.com \\ ${ }^{5}$ Universidade Popular Túlio Espanca da Universidade de Évora e SUÃO-Escola \\ Comunitária de São Miguel de Machede (PORTUGAL), suao.fazerbem@gmail.com
}

\section{Resumo}

Fundada em 2009, a Universidade Popular Túlio Espanca da Universidade de Évora (UPTE/UÉ) é, na atualidade, uma rede regional de educação popular com presença nos concelhos de Alandroal, Barrancos, Évora (Canaviais e São Miguel de Machede), Portel, Reguengos de Monsaraz e Viana do Alentejo. Assumindo um modelo de educação popular e comunitário, de perfil intergeracional, promovido em contextos não-formais e assente num trabalho cooperativo interinstitucional, no território do Alentejo, a UPTE/UÉ contribui para a concretização da missão da Universidade de Évora, através da sua atividade de extensão, junto das comunidades locais, para a qual são convocados os recursos científicos, culturais, pedagógicos, tecnológicos e humanos da academia. Neste trabalho apresentam-se os principais projetos educativos da UPTE/UÉ, nos quais a participação estudantil é privilegiada e enquadrada no âmbito dos respetivos percursos formais de formação. Através da UPTE/UÉ, os estudantes desenham e concretizam projetos de educação popular abertos à participação popular, com a supervisão dos seus docentes e no contexto das unidades curriculares que frequentam. Desta forma, os resultados e produtos das suas aprendizagens tornam-se um bem público que se disponibiliza, através de projetos educativos disponíveis à participação de públicos diferenciados e pouco frequentes no ensino superior.

Palavras-chave: universidade, currículo, educação popular, responsabilidade social.

\begin{abstract}
Founded in 2009, the Popular University Túlio Espanca of the University of Évora (UPTE / UÉ) is currently a regional network of popular education with presence in the municipalities of Alandroal, Barrancos, Évora (Canaviais and São Miguel de Machede), Portel, Reguengos of Monsaraz and Viana do Alentejo. Assuming a model of popular and community education, with an intergenerational profile, promoted in non-formal contexts and based on an interinstitutional cooperative work, in the Alentejo territory, UPTE / UÉ contributes to the accomplishment of the mission of the University of Évora, through its activity of extension to local communities, to which

\footnotetext{
1 Trabalho decorrente dos Projetos "Janelas Curriculares de Educação Popular no Ensino Universitário» e "Currículo, Educação Popular e Responsabilidade Social na Universidade», promovido pela Universidade Popular Túlio Espanca da Universidade de Évora e financiado pela Fundação Calouste Gulbenkian, no âmbito do Programa Gulbenkian Qualificação das Novas Gerações/ Projetos de desenvolvimento do ensino superior/Projetos inovadores no domínio educativo (edições 2014 e 2016).
} 
the scientific, cultural, pedagogical, technological and human resources of the Academy are being used for. This article presents the main educational projects of UPTE / UÉ, in which student participation is privileged and framed within the respective formal training pathways. Through UPTE / UÉ, students design and implement popular education projects open to popular participation, under the supervision of their teachers and in the context of the courses they attend. In this way, the results and products of their learning become a public good that becomes available through educational projects available to the participation of different and infrequent audiences in higher education.

Keywords: university, curriculum, popular education, social responsability.

\section{A UNIVERSIDADE POPULAR TÚLIO ESPANCA/UNIVERSIDADE DE ÉVORA}

A criação da Universidade Popular Túlio Espanca/Universidade de Évora (UPTE/UÉ) correspondeu a uma preocupação de a Universidade de Évora assumir uma maior interação com o território da Região Alentejo e as populações aí residentes, na concretização da sua missão, enquanto instituição de ensino superior. Neste pressuposto institucional e social, a UPTE/UÉ assumiu as seguintes finalidades:

1. Contribuir para a formação científica, cultural e técnica dos cidadãos da região Alentejo, através do acesso destes a modalidades de educação permanente e educação e formação ao longo da vida;

2. Reforçar a capacidade científica da Universidade de Évora, no âmbito da Educação não-formal, Educação Popular, Educação Comunitária, Educação de Adultos e Educação Permanente e Educação e Formação ao longo da vida;

3. Valorizar a infraestrutura pedagógica da Universidade de Évora, através da conceção e concretização de dispositivos de formação orientados para modelos e estilos de educação permanente e aprendizagem ao longo da vida e para públicos com interesses em ofertas de formação não formal em contextos não formais de aprendizagem;

4. Construir um espaço de interface entre a formação académica disponibilizada pela Universidade de Évora e a realidade da região, em áreas de forte significado e potencial para a população e com evidente contributo para a formação dos docentes, discentes e funcionários da Universidade de Évora;

5. Potenciar a utilização da infraestrutura humana, cultural, científica, pedagógica, técnica, tecnológica e física da Universidade de Évora e o respetivo aproveitamento, por parte da generalidade da população alentejana. (Nico \& Nico, 2016, p. 34)

O modelo de organização pedagógica institucional e o formato das diversas atividades de educação popular de matriz não formal e perfil intergeracional da (UPTE/UÉ) têm vindo a privilegiar a participação dos estudantes da academia eborense, de forma ativa e curricularmente articulada com os respetivos planos de estudos, sempre que tal seja possível e vantajoso.

A participação discente tem sido, aliás, um dos pilares de toda a arquitetura dos desenho e concretização dos principais projetos educativos da UPTE/UÉ, assumindo-se essa participação como uma marca diferenciadora desta iniciativa de extensão universitária, em execução há uma década na Universidade de Évora.

O envolvimento de estudantes universitários em projetos de educação popular é uma oportunidade de se concretizarem, concomitantemente, duas finalidades, que se consideram importantes, na respetiva formação:

i. A oportunidade de os estudantes universitários - preferencialmente com supervisão dos seus professores e no âmbito dos seus processos de aprendizagem e de avaliação acederem a contextos reais e, aí, participarem ou concretizarem projetos educativos, nos quais aplicam os conhecimentos e competências construídas no plano curricular da formação académica. Esta oportunidade valoriza, na academia e nas comunidades, os conhecimentos científicos, através da respetiva socialização e, dessa forma, também enriquece a própria formação dos estudantes, acrescentando-Ihe algumas competências não inscritas nos planos curriculares, mas muito relevantes numa formação mais humanista e atualmente muito consideradas no mercado de trabalho, nomeadamente: 
i) Competências de liderança:

a. Comunicar, assertiva e claramente;

b. Agir e decidir com responsabilidade e autonomia;

c. Trabalhar em equipa, considerando e valorizando a diversidade;

d. Resolver problemas.

ii) Competências de perfil humanista e axiológico:

a. Assumir atitudes, decisões e comportamentos solidários;

b. Respeitar e valorizar os conhecimentos não académicos de base experiencial;

c. Promover a cooperação intergeracional.

iii) Competências promotoras da capacidade de gestão pessoal da aprendizagem (Nico, 2001):

a. Competências de investigação:

i. Conhecer e utilizar as bases de dados disponíveis;

ii. Utilizar as tecnologias da informação e comunicação;

iii. Assumir padrões éticos no trabalho desenvolvido;

iv. Evidenciar humildade científica.

b. Competências de organização:

i. Organizar o trabalho;

ii. Gerir o tempo;

iii. Organizar e mobilizar a informação;

iv. Monitorizar os processos de trabalho e adaptá-los às circunstâncias.

c. Competências metacognitivas:

i. Avaliar o seu processo individual de trabalho e de aprendizagem;

ii. Alterar o perfil individual de trabalho e de aprendizagem em consequência de um, permanente e crítico, processo de avaliação. (Nico \& Nico, 2016, pp. 42-43)

ii. A oportunidade de os estudantes universitários contactarem com o território, as comunidades locais, a cultura local e os saberes experienciais das pessoas menos escolarizadas é um ensejo extraordinário de conhecerem um universo muito rico de conhecimentos, quase sempre ausentes das suas formações mais formais e académicas. Esta é uma oportunidade única de conciliar os dois universos: o mundo académico e o mundo real. Deste diálogo muito beneficiará a formação destes estudantes que aproveitam desta possibilidade.

Por outro lado, esta abordagem permite a concretização de outras finalidades mais relacionadas com os destinatários das atividades de educação popular:

i. Permite que as comunidades locais tenham uma oportunidade de aceder a contextos de educação não formal desenhados e concretizados por docentes e discentes universitários, nos quais se disponibilizam conhecimentos de perfil científico, cultural e artístico, normalmente menos frequentes nos contextos educativos comunitários;

ii. Permite a valorização local do conhecimento académico, através da perceção da sua natureza e da sua relevância social;

iii. Contribui para a valorização do conhecimento experiencial e, por consequência, das instituições locais que o promovem.

\section{AS «JANELAS CURRICULARES DE EDUCAÇÃO POPULAR»}

Dentro deste quadro conceptual, a UPTE/UÉ desenvolveu um modelo educativo denominado «Janelas Curriculares de Educação Popular», definido como sendo

episódios de educação popular de perfil não formal e intergeracional desenhados e concretizados no seio dos planos de estudo curriculares disponibilizados pela Universidade de Évora, no âmbito da sua oferta formativa regular. Estas atividades são previamente negociadas e definidas pelos docentes e discentes, nas unidades curriculares em que as mesmas ocorrem, e oportunamente divulgadas, no âmbito do projeto educativo da Universidade Popular Túlio Espanca, para cada ano letivo. (Nico \& Nico, 2016, p. 41) 
O objetivo geral deste projeto consiste em:

proporcionar, aos estudantes da Universidade de Évora, oportunidades de conceber, planificar e concretizar projetos de educação não formal abertos à participação da população do Alentejo, decorrentes da mobilização do conhecimento e da competência científica, cultural, técnica e tecnológica decorrente da respetiva formação académica e enquadrados, sempre que possível, no âmbito dos planeamentos didáticos das unidades curriculares frequentadas. O projeto assentou no pressuposto de que, em contexto curricular, é possível e qualitativamente vantajoso para a qualidade das aprendizagens, a substituição de alguns instrumentos didáticos e de avaliação pela participação discente em projetos de divulgação e promoção científicas, nos quais, se mobilizam e aplicam, em contexto de educação popular, os conhecimentos e as competências edificados na academia. Por outro lado, a certificação dessa participação, em complementaridade com a certificação académica tradicional, poderá valorizar e diferenciar o Curriculum Vitae dos estudantes participantes, porque o enriquece com competências habitualmente ausentes dos currículos académicos mas muito valorizadas em contextos profissionais. (Nico \& Nico, 2016, p. 48)

As «Janelas Curriculares», enquadradas na atividade regular de formação da Universidade de Évora têm vindo a concretizar-se no âmbito da fileira de formação em Ciências da Educação, particularmente no Curso de Licenciatura. Neste contexto, as «Janelas Curriculares» podem apresentar os seguintes perfis:

Categoria A: "Janela Curricular" que aglomera um fluxo de várias janelas e prevê uma atividade conjunta de diferentes atores, com vista a garantir aos cidadãos oportunidades de formação ao longo da vida, promovendo o entrosamento da Universidade com a sociedade envolvente.

Categoria B: "Janela Curricular" que implica o desenvolvimento de projetos promovidos por estudantes, avaliados pela sua atividade no âmbito de uma ou mais unidades curriculares.

Categoria C: Participação pontual de pessoal técnico, funcionários, estudantes e docentes da Universidade no desenvolvimento de projetos comunitários. Esta participação, no caso de serem estudantes, não será avaliada no âmbito de unidades curriculares.

Categoria D: Momentos de partilha e desenvolvimento de projetos com determinados agentes da sociedade civil, designadamente membros de associações, corporações, escolas, parceiros, etc. (Nico \& Nico, 2016, p. 50)

\section{SÍNTESE}

Uma década após o início do projeto da UPTE/UÉ e cinco anos após a primeira experiência de desenho e concretização de «Janelas Curriculares de Educação Popular», pode fazer-se um balanço do trabalho realizado e dos respetivos resultados (Nico \& Nico, 2016, p. 1). O conhecimento académico chegou a geografias humanas e sociais:

1. O conhecimento académico chegou a geografias humanas e sociais pouco frequentes na Universidade de Évora

Através do projeto «Janelas Curriculares de Educação Popular no Ensino Superior Universitário", foi possível envolver largas centenas de pessoas - de diversas localidades do Alentejo, diferentes origens sociais e distintos níveis de escolaridade - em atividades educativas, em contextos não formais e intergeracionais de aprendizagem, nas quais participaram, de forma cooperativa, membros da comunidade académica e das comunidades locais. De facto, como se pode verificar pela informação anteriormente disponibilizada nas fichas de cada uma das janelas curriculares, pessoas de todas as idades e oriundas dos concelhos de Alandroal, Portel e Viana do Alentejo e das freguesias eborenses de Canaviais e São Miguel de Machede participaram em diferentes projetos educativos desenhados e construídos por investigadores, professores, estudantes e colaboradores da Universidade de Évora, em estreita cooperação com autarcas, responsáveis institucionais e cidadãos da região. 
2. Diferentes saberes encontraram-se com diferentes pessoas, através de diferentes didáticas

Este projeto possibilitou a presença simultânea, nos contextos de aprendizagem construídos, de saberes de diferentes origens e com diversas didáticas associadas. Na realidade, o conhecimento académico interagiu e foi enriquecido com o conhecimento experiencial e vice-versa. Deste encontro, provocado e preparado, dos conhecimentos académico e experiencial, resultou sempre uma aprendizagem mais completa, porque mais diversa e inclusiva, para todos os participantes.

3. A participação no projeto deixou uma marca humana em cada participante Dificilmente mensurável, através dos dispositivos formais de avaliação disponíveis, a dimensão axiológica e emocional foi a mais presente no pensamento que prevaleceu ao desenho do projeto e terá sido, certamente, a que mais terá marcado os participantes, nomeadamente os que pertencem à academia. Aprendermos e podermos partilhar o resultado das nossas aprendizagens é um ato de solidariedade, num patamar a que não estamos muito habituados, mas, é um exercício de humanidade possível e marcante para quem trabalha na universidade, particularmente os estudantes.

4. A responsabilidade social institucional e a educação popular são realidades presentes e futuras na missão das universidades

O conhecimento académico pode e deve ser acedido de forma cada vez mais aberta e inclusiva, por parte dos cidadãos e dos territórios. As dimensões da produção e transferência do conhecimento científico e da cultura não são questões exclusivas ou circunscritas às dimensões da economia. $\mathrm{Na}$ realidade, a concretização do projeto «Janelas Curriculares de Educação Popular no Ensino Superior Universitário» demonstra que é possível dar uma utilidade social imediata ao conhecimento académico, através da sua disponibilização universal, através de dispositivos didáticos desenhados e concretizados de acordo com o perfil pessoal e institucional dos que neles vão participar. A educação popular - concretizada em contextos não formais e intergeracionais de aprendizagem - pode, aqui, assumir um papel muito importante, ao assegurar um novo acesso à Educação, por parte de um conjunto significativo de pessoas que, habitualmente, não acede a contextos educativos estruturados. Contribuir para a educação e a cultura dos territórios e das comunidades locais com que se relaciona é uma das mais nobres formas de as universidades concretizarem a sua responsabilidade social, enquanto instituições críticas nos processos de inovação e desenvolvimento humano e social. (Nico \& Nico, 2016, p. 87-88)

\section{REFERÊNCIA}

Nico, B., \& Nico, L. (2016). Janelas Curriculares de Educação Popular na Universidade de Évora. Ramada: Edições Pedago. 